ORIGINAL RESEARCH

\title{
Evaluation of a Novel Audit Tool for Medication Reconciliation at Hospital Discharge
}

\author{
Anne Holbrook, Heather Bannerman, Amna Ahmed, Michael Georgy, J Tiger Liu, Sue Troyan, \\ and Alice Watt
}

\begin{abstract}
Background: Discharge medication reconciliation (MedRec) is designed to reduce medication errors and inform patients and key postdischarge providers, but it has been difficult to implement routinely in Canadian hospitals.

Objectives: To evaluate and optimize a new discharge MedRec quality audit tool and to use it at 3 urban teaching hospitals.

Methods: The discharge MedRec quality audit tool, developed by the Canadian Patient Safety Institute and the Institute for Safe Medication Practices Canada, was assessed and modified to improve comprehensiveness, clarity, and quality. The modified tool was then used to evaluate the quality of the discharge MedRec process for adult patients discharged to home from the general internal medicine service at 3 academic hospitals. Postdischarge telephone interviews were conducted with consenting patients, their community pharmacists, and their family doctors.

Results: The audit tool required modification to include aspects of admission MedRec, high-risk medication discrepancies, and direct communication of discharge MedRec to key follow-up providers. Thirtyfive patients (mean age 67.7 years, standard deviation [SD] 18.0 years; 17 [49\%] women), with a mean of 8.8 (SD 4.5) prescribed medications at discharge, participated in the discharge MedRec evaluation. Documentation of any discharge MedRec was found for only 1 patient (3\%), and no discharge MedRec was carried out by pharmacists. Postdischarge follow-up interviews elicited major gaps in communication with community pharmacists and with family physicians, which could lead to serious medication errors.
\end{abstract}

Conclusions: The modified audit tool was useful for identifying gaps in the quality of discharge MedRec.

Keywords: medication error, hospital discharge, medication reconciliation, discharge prescription, quality improvement, accreditation

\section{Can J Hosp Pharm. 2019;72(6):421-7}

\section{RÉSUMÉ}

Contexte : Le bilan comparatif des médicaments (BCM) au moment du congé est conçu pour réduire les erreurs médicamenteuses et informer les patients ainsi que les principaux prestataires de soins de santé après le congé, mais sa mise en œuvre systématique dans les hôpitaux canadiens s'est heurtée à de grandes difficultés.

Objectifs : Évaluer et optimiser un nouvel outil d'évaluation de la qualité du BCM au moment du congé et l'utiliser dans trois hôpitaux universitaires urbains.

Méthodes : Cet outil développé par l'Institut canadien pour la sécurité des patients (ICSP) et l'Institut pour la sécurité des médicaments aux patients du Canada (ISMP) a fait l'objet d'une évaluation et d'une modification visant à améliorer son exhaustivité, sa clarté et sa qualité. Loutil modifié a ensuite servi à évaluer la qualité du processus du BCM pour des patients adultes ayant obtenu leur congé après un séjour dans un service général de médecine interne dans trois hôpitaux universitaires. Des entretiens téléphoniques après le congé ont été menés avec les patients consentants, leur pharmacien communautaire et leur médecin de famille.

Résultats : L'outil d'évaluation a dû être modifié pour inclure le BCM au moment de l'admission, des écarts de médication à haut risque et une communication directe du BCM aux prestataires de soins de santé principaux chargés du suivi après le congé. Trente-cinq patients (âge moyen : 67,7 ans; écart type [ET] 18 ans; 17 [49\%] femmes), chacun ayant reçu en moyenne 8,8 (ET 4,5) médicaments prescrits, ont participé à l'évaluation du BCM au congé de l'hôpital. Au moment du congé, on n'a trouvé de renseignements relatifs au BCM que pour un seul patient (3\%) et aucun BCM n'avait été préparé par les pharmaciens. Le suivi après le congé a généré des écarts de communication importants entre les pharmaciens communautaires et les médecins de famille, ce qui pourrait entraîner des erreurs médicamenteuses importantes.

Conclusions : L'outil d'évaluation modifié a été utile pour déterminer les écarts relatifs à la qualité du BCM au moment du congé.

Mots-clés : erreur de médication, congé de l'hôpital, bilan comparatif des médicaments, prescription au moment du congé, amélioration de la qualité, accréditation 


\section{INTRODUCTION}

$\mathrm{M}$ edication error and therapeutic misadventure are thought to be leading causes of preventable patient harm resulting in serious outcomes, including hospital admission and premature death. ${ }^{1,2}$ A prospective single-arm cohort study in a Vancouver teaching hospital suggested that $12.0 \%$ of emergency department visits were drug-related, of which $68.0 \%$ were considered preventable and $36.9 \%$ led to hospital admission with a more prolonged length of stay than non-drug-related admissions. ${ }^{3}$ The landmark Canadian Adverse Events Study, published in 2004, found that errors with drugs and fluids were the most common cause of harm for inpatients on internal medicine services country-wide, at $42.6 \%$ of total errors. ${ }^{4}$ The overall fatality rate of $20.8 \%$ combined with estimated preventability of $36.9 \%$ suggest that there may be up to 5608 preventable deaths in Canadian hospitals each year due to medication error. ${ }^{4}$ The US Institute of Medicine has estimated that medication errors cause more deaths every year in the United States than motor vehicle crashes or breast cancer. ${ }^{5}$ A recent report from the United Kingdom suggests that medication errors plus drugs of abuse account for more than a third of avoidable deaths. ${ }^{6}$

Transitions in and out of hospital create opportunities for medication errors. ${ }^{7-9}$ Unintended medication discrepancies - that is, unaccounted variations from the patient's last known medication list-are an imperfect but commonly used surrogate for medication errors. ${ }^{10}$ Errors in medication histories at admission are common, occurring in up to $67 \%$ of cases, and many are potentially clinically important. ${ }^{8,11-14}$ Fragmented communication in these transitions has been previously documented as a major problem. ${ }^{15,16}$

Although medication discrepancies at admission are important, discrepancies at discharge may result in a higher number of potential adverse drug events. ${ }^{17}$ A study of 204 medical-surgical inpatients showed that more than half experienced medication discrepancies during their hospital stay, with 59\% of the discrepancies likely to have caused patient harm if the error continued after discharge. ${ }^{18}$ In a study completed at a Canadian tertiary care hospital, $70.7 \%$ of internal medicine patients had at least 1 actual or potential unintentional medication discrepancy at hospital discharge, with $29.5 \%$ of the errors judged to be potentially clinically significant. ${ }^{19}$

Despite potential benefit, there continues to be no evidence that patient outcomes are improved by medication reconciliation (MedRec) itself. ${ }^{20-23}$ However, discharge MedRec is mandated by national hospital accreditation bodies in Canada and the United States ${ }^{24,25}$ and has been recommended by the National Institute of Health and Care Excellence in the United Kingdom. ${ }^{26}$ A recent randomized trial suggested that extensive discharge MedRec, with direct communication to community providers plus several motivational interviews with patients, might reduce readmissions at 6 months. ${ }^{27}$ To date, there has not been a standardized, validated tool or methodology to carry out discharge MedRec, a possible reason why it has failed to affect clinical outcomes. The Canadian Patient Safety Institute, the Institute for Safe Medication Practices Canada (ISMP Canada), and others recently developed standardized tools for assessing the quality of MedRec both at hospital admission and at discharge. ${ }^{28,29}$

Our objective in this study was to evaluate a new discharge MedRec quality audit tool and to then use it to evaluate the quality of discharge MedRec in 3 academic teaching hospitals.

\section{METHODS}

Ethics approval was obtained from the Hamilton Integrated Research Ethics Board (13-841 and 13-842). The research was conducted in accordance with the principles set forth in the Helsinki Declaration.

\section{Study Design and Setting}

This retrospective observational pilot study was conducted at the Juravinski Hospital, Hamilton General Hospital, and St Joseph's Healthcare Hamilton between 2015 and 2018.

\section{Participants and Recruitment}

Patients were eligible for inclusion in the study if they were 18 years of age or older, English-speaking, hospitalized for at least $24 \mathrm{~h}$, and discharged to home. Exclusion criteria included discharge to a long-term care facility (where medications are administered by nursing staff) and receipt of palliative care. Patients provided written informed consent. If the patient was unable to consent, a caregiver could consent on the patient's behalf.

Eligible patients and their caregivers were approached within 2 days before discharge. Rolling week-long recruitment periods in each hospital took place, with a target sample size of 30 patients across all 3 hospitals, without a requirement for equal numbers per site. The patients' consent forms and an overview of the study were then faxed to their respective family physicians and community pharmacies to inform them of patient enrolment and to request permission to interview them about MedRec communication with the patient.

\section{Data Collection}

We carried out an initial pilot test of the discharge MedRec quality audit tool..$^{30}$ This audit tool included checklists identifying sources of information, completeness of the discharge prescription, discrepancies, rationale for discrepancies, resolution of discrepancies, and communication of discharge medication information. Notes regarding the quality of the audit tool as well as suggestions for improvement were recorded, and the tool was modified accordingly. The tool was then tested at the 3 study sites.

Hospital charts for eligible patients were reviewed, including admission notes; best possible medication history $(\mathrm{BPMH})$ on admission, if available; Drug Profile Viewer for Ontario Drug 
Benefit recipients, if available ${ }^{31}$; discharge prescription; discharge notes regarding medications; and discharge summaries. Each participant's pharmacy was contacted and asked to provide the patient's medication profile for the 6 months before admission. Presence and absence of these files and types of information, as well as medication discrepancies between the individual files, were recorded for data analysis.

A best possible medication discharge plan (BPMDP) was constructed by reviewing the discharge prescription, the medication administration record for the day of discharge, and the BPMH (either as documented in the chart or created by the investigators, if not present in the chart).

\section{Telephone Interviews}

Within 7 days after each participant's discharge from hospital, investigators attempted to contact the participant, the participant's community pharmacy, and the participant's family physician for phone interviews.

The participant interview gathered information about satisfaction with the admission and discharge MedRec processes, what the patient did with the discharge prescription, the patient's understanding of the discharge medications, and satisfaction with the community pharmacy's and family physician's awareness of medication changes after discharge.

The interview with the participant's community pharmacist asked whether the pharmacy had received a discharge prescription and whether changes had been made to the patient's medication regimen. If so, the pharmacy was asked whether these changes had been made clear on the discharge prescription.

The interview with the participant's family physician asked whether the patient had already attended a follow-up postdischarge appointment, whether the physician's office had received a copy of the discharge prescription or discharge summary, and whether any changes to preadmission medications were made clear.

\section{Outcomes}

The primary outcome was the usability of the discharge MedRec quality audit tool for internal medicine patients. Secondary outcomes included the quality of the discharge process for medications and the postdischarge opinions of patients, community pharmacists, and family physicians regarding the effectiveness of MedRec at discharge.

\section{Analysis}

The analysis was descriptive. Information collected through hospital chart review and phone interviews was entered into a Microsoft Excel database (Microsoft Corporation, Redmond, Washington). After training on chart review and data analysis, 2 of the investigators (H.B., A.A.) independently reviewed all information obtained during the data collection phase, and entered data on discrepancies between the $\mathrm{BPMH}$, discharge summary, and discharge prescriptions, while another investigator (A.H.) assessed the clinical importance of the discrepancies identified using the US Institute for Safe Medication Practices' designation for high-alert medications in the ambulatory setting (i.e., medications that are more likely to result in adverse clinical outcomes if administered incorrectly). ${ }^{32}$ Disagreements were resolved by repeat review and consensus.

The completeness, readability, and quality of the discharge prescription itself were also rated (e.g., inclusion of legible prescriber signature, printed full name, and College of Physicians and Surgeons of Ontario number).

\section{RESULTS}

We recruited 35 patients from the 3 Hamilton teaching hospitals, with a mean age of 67.7 years (standard deviation [SD] 18.0; range 22-97), of whom 17 (49\%) were women (Table 1). The mean number of prescribed medications at discharge was 8.8 (SD 4.5).

Table 1. Baseline Characteristics

\begin{tabular}{|c|c|}
\hline Characteristic & $\begin{array}{c}\text { No. }(\%) \text { of } \\
\text { Participants* } \\
(n=35)\end{array}$ \\
\hline \multicolumn{2}{|l|}{ Participants by site } \\
\hline Site 1 & $16(46)$ \\
\hline Site 2 & $10(28)$ \\
\hline Site 3 & $9(26)$ \\
\hline Age (years) (mean \pm SD) & $67.7 \pm 18.0$ \\
\hline \multicolumn{2}{|l|}{$\operatorname{Sex}$} \\
\hline Male & $18(51)$ \\
\hline Female & $17(49)$ \\
\hline Hospital length of stay (days) (mean \pm SD) & $6.4 \pm 6.0$ \\
\hline $\begin{array}{l}\text { Interval between discharge and patient } \\
\text { interview (days) (mean } \pm \text { SD) }\end{array}$ & $11.0 \pm 6.0$ \\
\hline $\begin{array}{l}\text { No. of prescription medications at } \\
\text { discharge (mean } \pm \text { SD) }\end{array}$ & $8.8 \pm 4.5$ \\
\hline Best possible medication history on file & $11(31)$ \\
\hline Discharge prescription received at discharge & $33(94) \dagger$ \\
\hline \multicolumn{2}{|l|}{$\begin{array}{l}\text { Type of physician signing discharge } \\
\text { prescription }(n=33)\end{array}$} \\
\hline Resident & $19(58)$ \\
\hline Attending physician & $13(39)$ \\
\hline No signature & $1(3)$ \\
\hline $\begin{array}{l}\text { Discharge prescription included printed name } \\
\text { of prescriber }(n=33)\end{array}$ & $22(67)$ \\
\hline $\begin{array}{l}\text { Discharge prescription included licence number } \\
\text { of prescriber }(n=33)\end{array}$ & $22(67)$ \\
\hline \multicolumn{2}{|l|}{ Interviews } \\
\hline $\begin{array}{l}\text { With patients or caregivers } \\
\text { (median time after discharge: } 9 \text { [IQR 6] days) }\end{array}$ & $31(89)$ \\
\hline $\begin{array}{l}\text { With patient's community pharmacist } \\
\text { (median time after discharge: } 9 \text { [IQR 6] days) }\end{array}$ & $35(100)$ \\
\hline $\begin{array}{l}\text { With patient's family physician } \\
\text { (median time after discharge: } 13 \text { [IQR 24] days) }\end{array}$ & $32(91) \ddagger$ \\
\hline \multicolumn{2}{|c|}{$\begin{array}{l}\text { IQR = interquartile range, SD = standard deviation. } \\
\text { *Except where indicated otherwise. } \\
\text { †Two patients were advised to resume their home medications at } \\
\text { discharge. } \\
\text { †Three patients had no family physician. }\end{array}$} \\
\hline
\end{tabular}


This single copy is for your personal, non-commercial use only.

For permission to reprint multiple copies or to order presentation-ready copies for distribution, contact CJHP at publications@cshp.pharmacy

\section{Evaluation and Modification of the Discharge MedRec Quality Audit Tool}

The tool was judged to be missing some key items, which were added to create a modified discharge MedRec tool, as shown in Figure 1. We added items regarding admission MedRec (i.e., the BPMH), high-risk medications, and number of discrepancies. The modified discharge MedRec quality audit tool was judged to have good utility and was easy to use for subsequent assessment of the quality of the discharge MedRec process. Audit questions about prescription details (dose, strength, route of administration, frequency, and duration for each medication; documentation of rationale for medication changes; whether changes to medications were reviewed with the patient and/or caregiver; and whether changes to medications were communicated to community health care providers) were thought to have good face validity for assessing the quality of discharge MedRec.

\section{Quality of MedRec}

The quality of MedRec was evaluated for all 35 participants (Table 2). Eleven (31\%) of the participants had MedRec completed upon admission (as the BPMH). Of these 11, the BPMH clarified additional medications or dosages in 7 (64\%) cases. Mention of a formal discharge MedRec was found for only 1 patient. In 17 cases (49\%), it was clear that the discharge prescription had been written directly from the medication administration record on the day of discharge, and up to one-third of prescriptions were missing important information, such as legible prescriber identification or medication details. Using our reconstructed BPMH and BPMDP, we noted a large number of medication discrepancies, involving 22 (63\%) of the patients. For 9 (41\%) of these 22 patients, unexplained discrepancies involved high-alert medications (as identified by the US Institute for Safe Medication Practices), medications that are more likely to result in adverse clinical outcomes if administered incorrectly. ${ }^{32}$ The rationale for medication changes was documented somewhere in the chart in $6(17 \%)$ cases, but none of these charts stated whether the changes had been reviewed with the patient or caregiver at any point.

\section{Postdischarge Interviews}

Thirty-one (89\%) of the 35 participants were interviewed (Table 2). One patient died before the interview date, and 3 of the patients could not be reached by phone, despite a minimum of 7 call attempts. Twelve (39\%) of the 31 participants recalled admission MedRec (BPMH), although only 11 had documentation of admission MedRec in their charts. Several patients noted problems with administration of their medications in hospital, mainly changes in administration times or product substitution. Twenty patients $(65 \%)$ recalled a "discharge MedRec" process, whereas the criteria for a full review of medications and changes

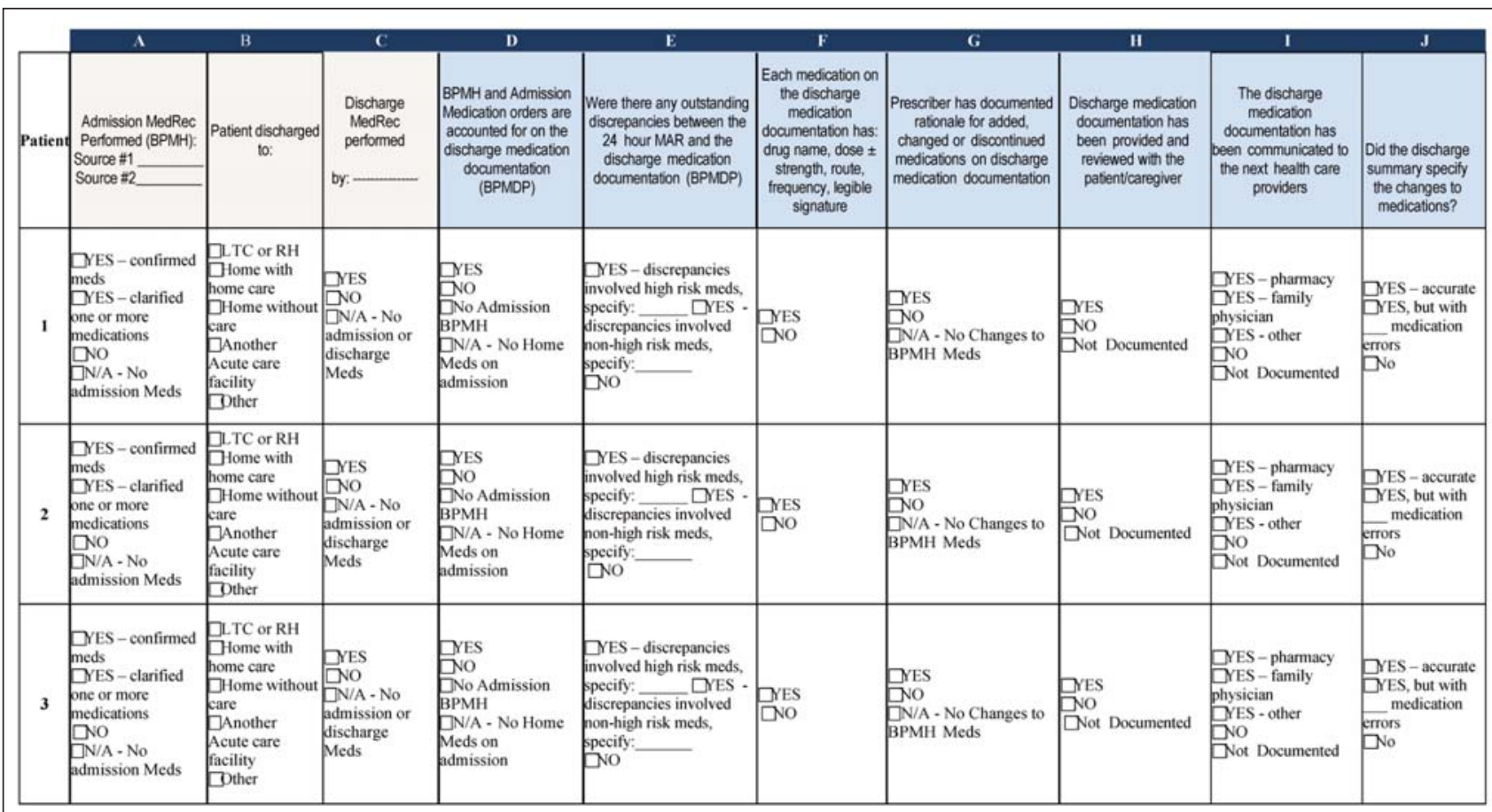

Figure 1. Revised discharge medication reconciliation quality audit tool, with one row per patient (additional rows can be added as needed). BPMDP = best possible medication discharge plan, BPMH = best possible medication history, LTC = long-term care, MAR = medication administration record, N/A = not available, $\mathrm{RH}=$ retirement home. 
Table 2. Results of Chart Audit and Interviews

\begin{tabular}{lc} 
Element of Chart Audit or Interview & $\begin{array}{c}\text { No. (\%) of } \\
\text { Participants } \\
(\boldsymbol{n}=\mathbf{3 5 *}\end{array}$ \\
\hline Chart audit & \\
BPMH clarified admission medications or doses & $7(20)$ \\
Yes & $4(11)$ \\
No & $24(69)$ \\
NA (no BPMH completed by care team) & 1 \\
Discharge MedRec was performed & $(3)$ \\
Yes: discharge MedRec noted in chart & $32(91)$ \\
No: discharge prescription only & $2(6)$ \\
No: neither discharge MedRec nor discharge & \\
$\quad$ prescription provided & $17(49)$ \\
\hline Sources of information used for discharge prescription & \\
Medication administration record & $16(46)$ \\
Not stated & $2(6)$ \\
NA & $(6)$ \\
\hline Unexplained differences between reconstructed BPMH and BPMDP \\
Yes: involving high-risk medications & $9(26)$ \\
Yes: not involving high-risk medications & $13(37)$ \\
No & $11(31)$ \\
NA & $2(6)$ \\
\hline
\end{tabular}

Each medication on discharge prescription has drug name, dose, route, frequency

\begin{tabular}{lrr} 
Yes & $31(89)$ \\
No & 2 & $(6)$ \\
NA & 3 & $(4)$ \\
\hline Discharge summary specifies medication changes & \\
Yes & $17(49)$ \\
No & $18(51)$ \\
\hline Rationale for medication changes documented & $6(17)$ \\
Yes & $26(74)$ \\
No & $3(9)$ \\
NA &
\end{tabular}

\section{Interviews}

Patient noted problems with medications in hospital ( $\mathrm{n}=31$ patients)

Yes $8(26)$

No 21 (68)

Can't remember $2(6)$

Medications were discussed at discharge $(\mathrm{n}=31$ patients)

Yes, and was useful 13 (42)

Yes 7 (23)

No, would have been useful to discuss 4 (13)

No 6 (19)

Can't remember $\quad 1$

Yes 28 (80)

No 5 (14)

NA (no discharge prescription provided to patient) 2 (6)

Pharmacist had to clarify discharge prescription ( $\mathrm{n}=35$ pharmacists)

Yes 10 (29)

No 18 (51)

NA (no discharge prescription received) 7 (20)

Discharge documentation was received by family physician

( $\mathrm{n}=32$ physicians)

Both discharge prescription and discharge summary 7 (22)

Discharge prescription only 3 (9)

Discharge summary only 18 (56)

Don't know 4 (13)

Family physician had to clarify discharge prescription

( $n=32$ physicians)

Yes

No

3 (9)

$20(63)$

Can't remember

$9(28)$

BPMH/BPMDP = best possible medication history/discharge plan, MedRec = medication reconciliation, NA = not applicable

*Except where indicated otherwise. at discharge were met for only 1 patient. Nonetheless, 13 (42\%) of those interviewed felt that the limited discussion had been useful.

All 35 community pharmacists (100\%) were interviewed. Five $(14 \%)$ of the pharmacists noted that they had not received the discharge prescription that was prepared for the patient. Two recalled that the patient involved had deliberately withheld the new prescription because of changes made during the hospital stay (decrease in dose of opioids, discontinuation of benzodiazepines). The pharmacists noted problems that required clarification in $10(36 \%)$ of the 28 discharge prescriptions received.

Thirty-two (91\%) of the patients had family physicians, each of whom was interviewed. Twenty-eight (88\%) of these family physicians had received discharge documents from the hospital, but only $10(31 \%)$ had received a copy of the discharge prescription. Three (11\%) of the 28 physicians with discharge documents of some kind reported confusion about the discharge prescription, and $2(7 \%)$ had restarted medications that they did not realize had been stopped in hospital.

\section{DISCUSSION}

This study was the first evaluation of the discharge MedRec quality audit tool. Once modified to include information about the admission MedRec and more detailed information about discrepancies, the modified tool was thought to be highly useful for assessing the quality of the discharge MedRec. We found that an accurate discharge MedRec relied on an accurate BPMH and documentation of patient information influencing medication choices and doses (e.g., renal function, allergies). Following up with patients and their community providers after discharge added valuable additional information, primarily showing that the level of communication expected in a high-quality discharge MedRec was lacking. In addition, we uncovered a few examples of patients deliberately disrupting discharge prescription updates to their medications (by not taking the discharge prescription to their pharmacy) to regain access to high doses of opioids or benzodiazepines. As well, family physicians were unwittingly restarting medications that had been stopped while the patient was in hospital, a practice with potentially adverse clinical outcomes. Both of these types of miscommunication could have been avoided by transmitting the discharge prescription with full reconciliation directly to community care providers. Analyses of discharge MedRec have identified frequent medication discrepancies at the time of discharge $e^{33}$, and the "silos" of Canadian health care do not facilitate seamless postdischarge MedRec.

Our study had several limitations, including the small sample size, the single large community, and the retrospective design. For many patients, we had to reconstruct the $\mathrm{BPMH}$, which may have led to errors, particularly given that some patients take their medications quite differently from instructions on the prescription label. Despite these limitations, our pilot was informative on 
This single copy is for your personal, non-commercial use only.

For permission to reprint multiple copies or to order presentation-ready copies for distribution, contact CJHP at publications@cshp.pharmacy

3 main fronts. First, the proposed discharge MedRec quality audit tool had some significant gaps, but once these were addressed, the modified tool was easy to use and had good face validity. Second, application of the tool identified major limitations in the quality of discharge MedRec, often beginning with no or limited admission MedRec. Third, direct postdischarge communication with key stakeholders in the community, starting with sending a copy of the discharge prescription directly to the community pharmacy and to the patient's primary care provider, is necessary to avoid unintended or intended medication errors.

\section{CONCLUSION}

The modified discharge MedRec audit tool can aid in the improvement of hospital discharge MedRec processes nationally by serving as a quality checklist or reminder of process steps. Further research is needed to improve the efficiency of this potentially time-consuming and costly process and to evaluate whether a high-quality discharge MedRec process can improve patient outcomes or be cost-effective on its own or as a component of expert medication management. Several ongoing randomized trials are testing the effectiveness of expert medication management in the transition period from hospital to home. ${ }^{34,35}$

\section{References}

1. de Vries EN, Ramrattan MA, Smorenburg SM, Gouma DJ, Boermeester MA. The incidence and nature of in-hospital adverse events: a systematic review. Qual Saf Health Care. 2008;17(3):216-23.

2. Pirmohamed M, James S, Meakin S, Green C, Scott AK, Walley TJ, et al. Adverse drug reactions as cause of admission to hospital: prospective analysis of 18820 patients. BMJ. 2004;329(7456):15-9.

3. Zed PJ, Abu-Laban RB, Balen RM, Loewen PS, Hohl CM, Brubacher JR, et al. Incidence, severity and preventability of medication-related visits to the emergency department: a prospective study. CMAJ. 2008;178(12):1563-9.

4. Baker GR, Norton PG, Flintoft V, Blais R, Brown A, Cox J, et al. The Canadian Adverse Events Study: the incidence of adverse events among hospital patients in Canada. CMAJ. 2004;170(11):1678-86.

5. Kohn L, Corrigan J, Donaldson M. To err is human: building a safer health system. Washington (DC): National Academy Press; 1999.

6. Elliott R, Camacho E, Campbell F, Jankovic D, Martyn St James M, Kaltenthaler E, et al. Prevalence and economic burden of medication errors in the NHS in England. Rapid evidence synthesis and economic analysis of the prevalence and burden of medication error in the UK. Sheffield and York (UK): Universities of Sheffield and York, Policy Research Unit in Economic Evaluation of Health and Care Interventions; 2018.

7. Bates DW, Cullen DJ, Laird N, Petersen LA, Small SD, Servi D, et al. Incidence of adverse drug events and potential adverse drug events: implications for prevention. ADE Prevention Study Group. JAMA. 1995; 274(1):29-34

8. Tam VC, Knowles SR, Cornish PL, Fine N, Marchesano R, Etchells EE. Frequency, type and clinical importance of medication history errors at admission to hospital: a systematic review. CMAJ. 2005;173(5):510-5.

9. Medication without harm. Geneva (CH): World Health Organization; 2017 [cited 2018 Nov 19 ]. Available from: http:/www.who.int/iris/handle/ $10665 / 255263$

10. Boockvar KS, Blum S, Kugler A, Livote E, Mergenhagen KA, Nebeker JR, et al. Effect of admission medication reconciliation on adverse drug events from admission medication changes. Arch Intern Med. 2011;171(9):860-1.

11. Hellstrom LM, Bondesson A, Höglund P, Eriksson T. Errors in medication history at hospital admission: prevalence and predicting factors. BMC Clin Pharmacol. 2012;12:9.
12. Belda-Rustarazo S, Cantero-Hinojosa J, Salmeron-García A, González-García L, Cabeza-Barrera J, Galvez J. Medication reconciliation at admission and discharge: an analysis of prevalence and associated risk factors. Int J Clin Pract. 2015;69(11):1268-74.

13. Rodríguez Vargas B, Delgado Silveira E, Iglesias Peinado I, Bermejo Vicedo T. Prevalence and risk factors for medication reconciliation errors during hospital admission in elderly patients. Int J Clin Pharm. 2016;38(5):1164-71.

14. Ashcroft DM, Lewis PJ, Tully MP, Farragher TM, Taylor D, Wass V, et al. Prevalence, nature, severity and risk factors for prescribing errors in hospital inpatients: prospective study in 20 UK hospitals. Drug Saf. 2015;38(9): 833-43.

15. Holbrook A, Bowen JM, Patel H, O’Brien C, You JJ, Tahavori R, et al. Process mapping evaluation of medication reconciliation in academic teaching hospitals: a critical step in quality improvement. BMJ Open. 2016;6(12):e013663.

16. The National Patient Experience Survey: findings of the 2017 inpatient survey. National Patient Experience Survey [Ireland]; 2017 [cited 2018 Nov 14] Available from: https://yourexperience.ie/wp-content/uploads/2019/07/ NPES-National-Report-2017-WEB.pdf

17. Pippins JR, Gandhi TK, Hamann C, Ndumele CD, Labonville SA, Diedrichsen EK, et al. Classifying and predicting errors of inpatient medication reconciliation. J Gen Intern Med. 2008;23(9):1414-22.

18. Gleason KM, Groszek JM, Sullivan C, Rooney D, Barnard C, Noskin GA Reconciliation of discrepancies in medication histories and admission orders of newly hospitalized patients. Am J Health Syst Pharm. 2004; 61(16):1689-95.

19. Wong JD, Bajcar JM, Wong GG, Alibhai SM, Huh JH, Cesta A, et al. Medication reconciliation at hospital discharge: evaluating discrepancies. Ann Pharmacother. 2008;42(10):1373-9.

20. Shiu JR, Fradette M, Padwal RS, Majumdar SR, Youngson E, Bakal JA, et al. Medication discrepancies associated with a medication reconciliation program and clinical outcomes after hospital discharge. Pharmacotherapy. 2016;36(4):415-21.

21. Christensen M, Lundh A. Medication review in hospitalised patients to reduce morbidity and mortality. Cochrane Database Syst Rev. 2016;2: CD008986.

22. Redmond P, Grimes TC, McDonnell R, Boland F, Hughes C, Fahey T. Impact of medication reconciliation for improving transitions of care. Cochrane Database Syst Rev. 2018;8:CD010791.

23. Urban R, Armitage G, Morgan J, Marshall K, Blenkinsopp A, Scally A. Custom and practice: a multi-center study of medicines reconciliation following admission in four acute hospitals in the UK. Res Social Admin Pharm. 2014;10:355-68.

24. Required organizational practices: handbook 2017. Version 2. Ottawa (ON): Accreditation Canada; 2017 [cited 2019 Oct 31]. Available from: https:// www3.accreditation.ca/OrgPortal/Documents/Resources/AddResources/ ROPHandbook_2017_v2_EN.pdf

25. National patient safety goals effective January 2019: hospital accreditation program. Oakbrook Terrace (IL): The Joint Commission; 2019 [cited 2019 Oct 31]. Available from: https://www.jointcommission.org/assets/1/6/ NPSG_Chapter_HAP_Jan2019.pdf

26. NICE Guideline NG5: Medicines optimisation: the safe and effective use of medicines to enable the best possible outcomes. London (UK): National Institute for Health and Care Excellence; 2015 [cited 2018 Sep 26]. Available from: nice.org.uk/guidance/ng5

27. Ravn-Nielsen L, Duckert ML, Lund ML, Henriksen JP, Nielsen ML, Eriksen $\mathrm{CS}$, et al. Effect of an in-hospital multifaceted clinical pharmacist intervention on the risk of readmission: a randomized clinical trial. JAMA Intern Med. 2018;178(3):375-82.

28. Medication reconciliation (MedRec). Toronto (ON): Institute for Safe Medication Practices Canada; (C) 2008-2019 [cited 2018 Nov 14]. Available from: https://www.ismp-canada.org/medrec/

29. Medication reconciliation in acute care. Getting started kit. Version 4. Canadian Patient Safety Institute and Institute for Safe Medication Practices Canada; 2017 [cited 2018 Nov 14]. Available from: https://www.ismp-canada.org/ download/MedRec/MedRec-AcuteCare-GSK-EN.pdf

30. Measures: medication reconciliation (MedRec). Edmonton (AB): Canadian Patient Safety Institute (CPSI); [cited 2018 Nov 26]. Available from http://www.patientsafetyinstitute.ca/en/toolsresources/psm/pages/ medrec-measurement.aspx 
31. Drug profile viewer [website]. Toronto (ON): eHealth Ontario; [cited 2016 Mar 3]. Available from: http://www.ehealthontario.on.ca/en/initiatives/ view/drug-profile-viewer

32. High-alert medications in community/ambulatory settings. Horsham (PA): Institute for Safe Medication Practices; 2011 Jan 31 [cited 2018 Nov 14]. Available from: https://www.ismp.org/recommendations/high-alertmedications- community-ambulatory-list

33. Michaelsen MH, McCague P, Bradley CP, Sahm LJ. Medication reconciliation at discharge from hospital: a systematic review of the quantitative literature. Pharmacy (Basel). 2015;3(2):53-71.

34. Clinical Trials.gov identifier NCT027770472016: Anticoagulant safety at hospital discharge [clinical trial registration]. Bethesda (MD): US National Library of Medicine, ClinicalTrials.gov; 2016 [cited 2018 Sep 26]. Available from: https://clinicaltrials.gov/ct2/show/record/NCT02777047?cond= anticoagulants\&rank $=2$

35. Clinical Trials.gov identifier NCT04077281: Improving Medication Prescribing-Related Outcomes for Vulnerable Elderly In Transitions (IMPROVE-IT) [clinical trial registration]. Bethesda (MD): US National Library of Medicine, Clinical Trials.gov; 2019 [cited 2019 Nov 15]. Available from: https://clinicaltrials.gov/ct2/show/NCT04077281?term=IMPROVEIT \&recrs $=\mathrm{b} \& \mathrm{draw}=2 \& \mathrm{rank}=1$

Anne Holbrook, MD, PharmD, MSC, FRCPC, is with the Division of Clinical Pharmacology \& Toxicology and the Department of Medicine, McMaster University, Hamilton, Ontario.
Heather Bannerman, MD, PharmD, BScPhm, is with the Internal Medicine Residency Program, Department of Medicine, McMaster University, Hamilton, Ontario.

Amna Ahmed, MD, is with the Department of Medicine, McMaster University, Hamilton, Ontario.

Michael Georgy, MBBCh, is a student currently affiliated with the Royal College of Surgeons in Ireland, Dublin, Ireland.

J Tiger Liu, MSc, was, at the time of this study, a student with the eHealth Master's Program, McMaster University, Hamilton, Ontario.

Sue Troyan, BA, is with the Division of Clinical Pharmacology \& Toxicology, St Joseph's Hospital Hamilton, Hamilton, Ontario.

Alice Watt, BSc(Pharm), RPh, is with the Institute for Safe Medication Practices Canada, Toronto, Ontario.

Competing interests: Alice Watt is employed by ISMP Canada, which developed the initial MedRec Audit tool. No other competing interests were declared.

\section{Address correspondence to:}

Dr Anne Holbrook

Division of Clinical Pharmacology \& Toxicology

McMaster University

SJHH G624, 50 Charlton Avenue E

Hamilton ON L8N 4A6

Funding: This study was supported by the Canadian Institutes for Health Research (study grant FRN-148803 to Anne Holbrook).

\section{ON THE FRONT COVER}

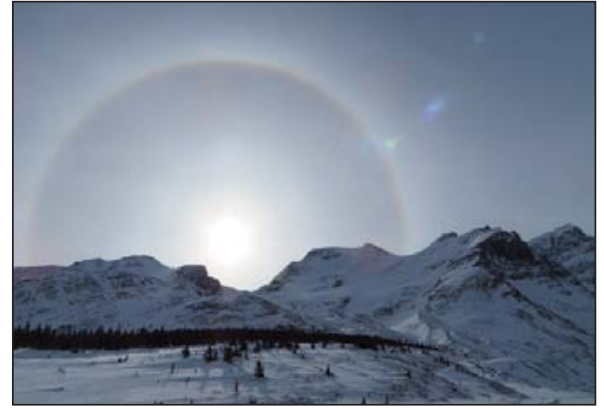

\section{Columbia Icefield Jasper National Park, Alberta}

Benton Attfield took the cover photo of a sundog in February 2017, at a location south of the Columbia Icefield in Jasper National Park, using a Canon PowerShot SX270 HS camera. Benton is a clinical pharmacist in the Emergency Department at Foothills Medical Centre in Calgary, Alberta. His practice areas of interest include addictions medicine, toxicology, and patient transitions of care. In addition to adventuring in the great outdoors on foot or bike, he enjoys cooking and exploring new cuisines.

The CJHP would be pleased to consider photographs featuring Canadian scenery taken by CSHP members for use on the front cover of the Journal. If you would like to submit a photograph, please send an electronic copy (minimum resolution $300 \mathrm{dpi}$ ) to publications@cshp.pharmacy. 